ISSN 2236-0859

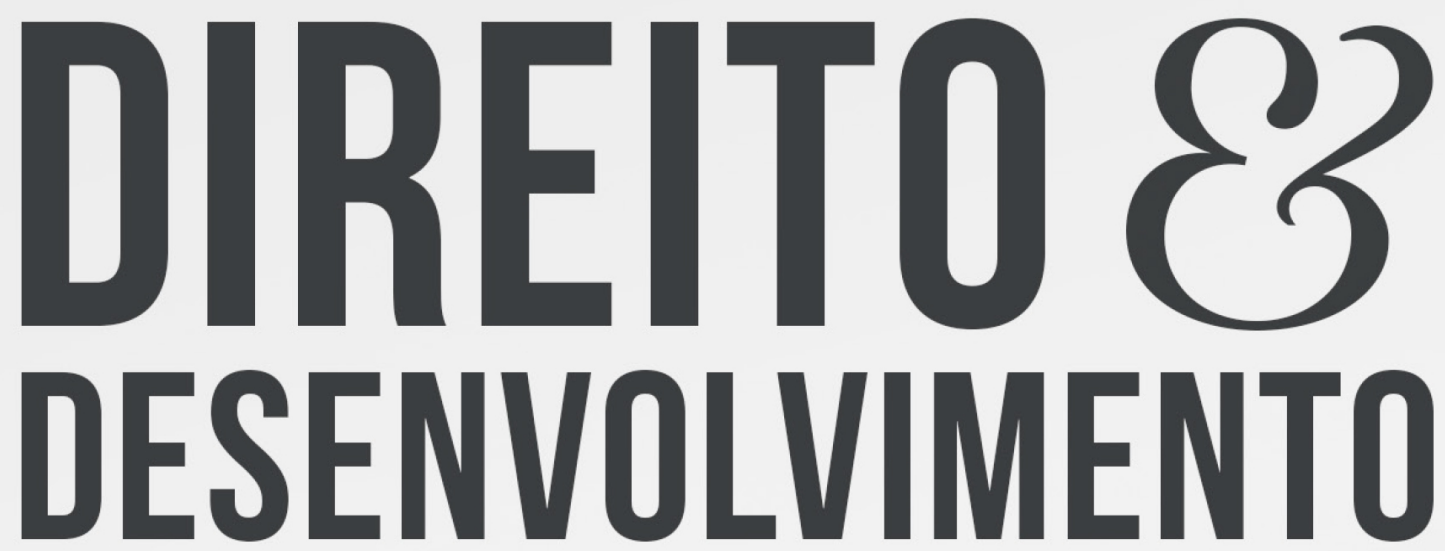

REVISTA DO PROGRAMA DE PÓS-GRADUAÇ̃̃O EM DIREITO MESTRADO EM DIREITO E DESENVOLVIMENTO SUSTENTÁVEL

\title{
PARTICIPAÇÃO DA MULHER NA POLITIICA BRASILEIRA
}

RICARDO SÉRVULL FONSÊCA DA COSTA ROGÉRIO MAGNUS VARELA GONÇALVES 


\title{
PARTICIPAÇÃO DA MULHER NA POLÍTICA BRASILEIRA
}

\section{WOMEN'S PARTICIPATION IN BRAZILIAN POLITICS}

Recebido: 30/09/2020

Aprovado: 21/07/2021
Ricardo Sérvulo Fonsêca da Costa ${ }^{1}$

Rogério Magnus Varela Gonçalves²

\section{RESUMO:}

A participação da mulher na política brasileira perpassa invariavelmente pela forma como o machismo se manifesta quando encontra mulheres ocupando lugares de prestígio que geralmente são preenchidos por homens. É inegável que em todas as partes do mundo as mulheres continuam sendo marginalizadas na esfera política uma vez que os cargos de poder foram historicamente ocupados por homens. Existem vários dados que comprovam como essa situação se perpetua até os dias de hoje e existem vários fatores que contribuem para a baixa participação das mulheres na política e para essa realidade ser assim, tão desigual. Âs vezes a baixa participação vem de leis discriminatórias e da falta de acesso das mulheres à educação, por vezes vem de práticas culturais que produzem estereótipos limitadores sobre o gênero feminino. Não é fácil para uma mulher chegar a um cargo de liderança e muitas vezes quando elas finalmente conseguem ocupar os espaços de poder majoritariamente masculinos, elas recebem uma enxurrada de julgamentos e ataques justamente por serem mulheres. Segundo dados divulgados pela União Inter-Parlamentar, o Brasil tem uma das taxas mais baixas do mundo de presença de mulheres no Congresso Nacional, ficando atrás até mesmo de países do Oriente Médio. Em que pese políticas públicas voltadas para incentivar a participação da mulher na política, sabe-se que esse espaço de poder continua sendo predominantemente masculino. O presente estudo se propõe a fazer um breve apanhado histórico da participação da mulher na política desde o seu início até os dias atuais. De modo a se alcançar o objetivo proposto, o aporte metodológico utilizado como subsídio ao estudo privilegiou material acadêmico e referências bibliográficas atinentes à matéria.

Palavras-chave: Mulher na política. Espaços de poder. Gênero feminino.

\begin{abstract}
:
Women's participation in brazilian politics invariably permeates the way the mechanism of manifestation when it finds women occupying prestigious places that are often filled by men. It

1 Doctor en Ciencias Jurídicas y Sociales pela Universidad Del Museo Social Argentino. Mestre em Direito pelo PPGD Unipe. Especialista em Direito Processual Civil pela UNP. Possui graduação em Direito pelo Centro Universitário de João Pessoa (1993). Atualmente é Procurador Geral do Município de Itabaiana-PB. Membro da Academia Brasileira de Direito Eleitoral e Político - ABRADEP. Membro da Academia Paraibana de Letras Jurídicas - APLJ. Professor universitário na FESP - Faculdades de Ensino Superior da Paraíba. Advogado - Ordem dos Advogados do Brasil. Jornalista e apresentador de TV, em programa jornalístico jurídico. Tem experiência na área de Direito. Email: rservuloadv@gmail.com

2 Graduado em Direito pela Universidade Federal da Paraíba (1996). Mestre em Ciências Jurídicas pela Universidade Federal da Paraíba (2002) e Doutor em Direito Constitucional na Universidade de Coimbra (2010). Doutorado revalidado pela Universidade Federal da Paraíba. É conselheiro federal - OAB - CONSELHO FEDERAL, tendo sido presidente da Comissão Nacional do Exame de Ordem e Membro da Comissão Nacional de Educação Jurídica (ambos do CFOAB - gestão de 2016 até 2019). Professor titular do Centro Universitário de João Pessoa. Membro permanente do Programa de Pós-Graduação em Direito (PPGD) do Centro Universitário de João Pessoa. Professor colaborador da Fundação Educacional Jayme de Altavila, Sócio Fundador do Varela e Negreiros Advogados Associados. Fundador do Instituto Eduardo Correia, professor da pós-graduação da Fundação Escola Superior do Ministério Público da Paraíba, professor da pós-graduação da Escola Superior da Advocacia, professor da pós-graduação da Escola Superior da Magistratura Trabalhista, professor da pós-graduação da Universidade Cândido Mendes e professor da pós-graduação da Universidade Potiguar. Tem experiência na área de Direito, com ênfase em Direito Constitucional, Administrativo e Municipal. Email: rogeriovarela@bol.com.br
\end{abstract}


is undeniable that in all parts of the world women continue to be marginalized in the political sphere, since the power burdens were historically occupied by men. There is a lot of evidence to see how this situation is perpetual to this day and there are a number of factors that contribute to the low participation of women in politics and in this reality to be so, so unequal. Sometimes low participation comes from discriminatory laws and women's lack of access to education, sometimes from cultural practices that produce limiting stereotypes about women. It is not easy for a woman to reach a leadership charge and often when they finally manage to occupy mostly male power spaces, they receive a flood of judgments and attacks by women only. According to data released by the Inter-Parliamentary Union, Brazil has one of the lowest rates in the world of women in Congress, behind the same country in the Middle East. In what public policies aimed at encouraging women's participation in politics, you know that this space of power remains predominantly male. This study aims to make a brief history of women's participation in politics from the beginning to the present day. In order to achieve the proposed objective, the methodological method used as a subsidy to the study privileged academic material and relevant bibliographical references.

Keywords: Woman in politics. Spaces of power. Feminine Gender.

\section{INTRODUÇÃO}

As mulheres sempre lutaram por melhores condições de emprego, salário e participação na política. Os obstáculos são muitos, de salários desiguais à falta de representatividade política. Política, que inclusive trata-se de uma palavra do gênero feminino que é dominada por homens. Sabe-se que a política acompanha o que acontece em vários setores da sociedade, e a desigualdade está em todos eles.

A lei eleitoral obriga que os partidos políticos tenham cotas para mulheres para justamente aumentar a representação feminina na política. Os partidos políticos são obrigados a preencher uma cota de $30 \%$ (trinta por cento) de candidatas em cada partido ou coligação.

Hoje, existe uma lei para a candidatura, mas não para garantir assentos, embora haja uma proposta de emenda constitucional (PEC) em tramitação. O problema da candidatura é que as vagas muitas vezes são preenchidas apenas para atender as cotas. O fundo partidário é de apenas $5 \%$ (cinco por cento) para garantir as candidaturas dessas mulheres e é fato notório que via de regra vence a campanha onde se deposita mais dinheiro, vence quem tem mais recursos. Nota-se que a obrigatoriedade das cotas muitas vezes não se converte em votos e resultado nas urnas.

Ocorre que a mentalidade dos partidos é que é necessário cumprir a cota, mas não existe o entendimento da real necessidade de inclusão das mulheres na política.

As cotas veem de um movimento internacional muito importante que ocorreu em 1995 em Pequim, e mais de 100 países no mundo adotam essa prática para mulheres na política porque viu-se a necessidade de inserção desse grupo nos espaços de poder políticos.

A dificuldade para que essa prática surta efeito no Brasil envolve uma série de questões, sendo a primeira delas o sistema eleitoral brasileiro que é um sistema de lista aberta e que faz com que todos os candidatos de um mesmo partido ou coligação disputem entre si, ocasionando que o vencedor dessa briga seja justamente aquele que teve mais dinheiro, se apenas $5 \%$ (cinco por cento) do fundo partidário é destinado às mulheres, por óbvio elas saem prejudicadas na disputa. Outro grande problema perpassa pela resistência dos partidos políticos em incluir mulheres, uma vez que eles não as identificam com capital político suficiente para atrair votos. 
Fala-se em focar na transparência dos partidos políticos para entender como essas mulheres candidatas são selecionadas, o tipo de apoio que elas recebem para que elas tenham chances efetivas de chegar ao final da disputa eleitoral e serem eleitas uma vez que não adianta a previsão legal de no mínimo 30\% (trinta por cento) de cotas destinadas à essas mulheres, se não será possível para elas a real chance de disputa em condições iguais as dos homens e em pé de igualdade.

As mulheres são a maioria da população, mas estão sub-representadas em vários setores da sociedade, na política são minoria e em pleno século 21 a voz feminina ainda é abafada pelo machismo e preconceito, a exemplo disso, e independentemente de suas posições políticas e/ ou viés ideológico, recorde-se dos fatos públicos e notórios de ataques misóginos que algumas mulheres na política sofreram e sofrem via mídias e redes sociais ao redor do mundo. Cite-se a atual vice-presidente da Argentina, Cristina Kirchner que foi retratada em capas de revistas de grande circulação nacional naquele país, nua e com expressão de regojizo como se estivesse inebriada pelo poder, cite-se a ex-presidente Dilma Roussef que à época de seu impeachment foi retratada também com uma expressão em close de seu rosto dando a entender que ela estava completamente alterada, e em surtos e que por isso, não teria condições de governar o país em virtude de seu descontrole emocional. Seguindo o fio da meada de casos internacionais, nos Estados Unidos as mulheres também são expostas a ataques machistas e misóginos, uma vez que Sara Palin, atual governadora do Alaska e uma das pessoas mais importantes dentro do partido republicano foi questionada em entrevista se ela teria aumentado os seios e trocado próteses de silicone, ou até mesmo Hillary Clinton que disputou as eleições presidenciais dos EUA com o atual presidente eleito Donald Trump, tentando ser a primeira mulher a se tornar chefe do poder executivo naquele país e dentre inúmeros ataques que sofreu durante a campanha, não por sua condição de candidata, e sim por ser mulher viu seu nome atrelado a um slogan de campanha que incentivava inclusive a violência contra a mulher, pois apoiadores do candidato que posteriormente viria a se tornar presidente dos EUA fizeram um trocadilho com o a palavra "thump" que em inglês significa "murro" e o sobrenome do presidente "Trump" numa frase que virou "Thump that bitch", algo como "esmurre aquela vadia", recurso de campanha visivelmente desrespeitoso e machista disfarçado de brincadeira eleitoral.

Um padrão que costuma se repetir é o de esteriotipar uma mulher que ascendeu politicamente de alguma forma, sendo a primeira opção taxá-la de castradora, mandona, autoritária que assusta os homens, e a segunda forma a de enquadrá-las é colocá-las no outro extremo, o da fragilidade, da mulher fraca, sem pulso. Não importa em qual dos extremos a mulher é colocada, ela acabará sendo menosprezada por sua condição de mulher.

Os exemplos citados foram de mulheres brancas e dentro de um determinado contexto, mulheres privilegiadas, quando se trata de mulheres negras que estão começando a ocupar cada vez mais espaços, a discriminação é dupla, pois elas sofrem a discriminação de gênero e a racial, vide o exemplo da atual vice-governadora do Estado do Piauí Regina Sousa que a época do fato era Senadora pelo mesmo Estado e foi chamada de "tia do café" pelo humorista Danilo Gentili. Nos EUA, Michelle Obama, esposa do ex-presidente Barack Obama e que participou ativamente das duas gestões do marido à frente da Casa Branca, foi atacada constantemente nas redes sociais sendo chamada de "macaca" e para sair do eixo Brasil-Estados Unidos, outro exemplo emblemático dessa dupla discriminação ao redor do mundo é Cécile Kyenge, política italiana nascida no Congo e que foi a primeira mulher negra a ocupar um ministério italiano. Cécile sofreu ameaças sexistas e insultos racistas que não partiram apenas da população em geral, mas também de colegas homens, deputados e pessoas que fizeram parte do governo italiano. 
No Brasil, algumas iniciativas tentam ajudar na transformação dessa realidade A lei 9096/1995, art. 45 determina que as legendas dediquem 10\% (dez por cento) do tempo de propaganda ao incentivo da participação das mulheres na política, sendo outro grande desafio conciliar as tarefas mais associadas ao gênero feminino com a vida pública uma vez que a mulher, via de regra não tem apenas uma atividade, tendo dois ou três trabalhos, tendo em vista que ao sair do expediente ainda continua trabalhando em casa e sendo dessa forma sobrecarregada e não encontrando condições para assumir outro tipo de atividade.

A participação da mulher brasileira na política ainda é muito pequena, em todas as casas legislativas. Comparando com outros países, o Brasil ocupa uma das piores posições do mundo entre os países da América Latina.

As mulheres precisam ocupar esse espaço de poder para que elas possam falar por mulheres formulando políticas públicas voltadas para as mulheres, e em virtude disto essa representatividade se faz necessária.

Quando não existe essa representação feminina que impacta diretamente nas tomadas de decisões políticas da sociedade ocorrem uma série de consequências.

No Brasil, se olharmos para as câmaras de vereadores, há muitas onde não há uma mulher sequer compondo as assembleias. Quando se coloca pessoas com perspectivas e experiências diversas dentro de um ambiente político de tomadas de decisão para a sociedade como um todo, é importante que haja opiniões contrárias à da maioria para justamente chegar a melhores decisões pensadas, refletidas e mais dialogadas porque é pensado no bem comum, e quando há mulheres ocupando esses espaços trazendo as pautas das mulheres para discussões há uma maior contribuição para que o resultado almejado seja alcançado.

Os desafios e dificuldades de inclusão de mulheres na política são inegáveis e trazem claramente as marcas da desigualdade de gênero.

Muito se fala sobre a questão da renovação política e a representatividade torna-se essencial para que se tenha uma política e democracia mais eficientes e que de fato representem o interesse de todos.

O presente artigo busca discutir o nível de representatividade que as mulheres possuem no cenário político brasileiro e apresentar um breve histórico da participação feminina na política.

\section{HISTÓRIA DAS MULHERES NA POLÍTICA BRASILEIRA}

A mulher entrou para o mercado de trabalho na segunda metade do século 18, durante a Revolução Industrial. Naquela época os salários eram até 6o\% (sessenta por cento) menores que o dos homens. Por conta disso, surgiram protestos contra a exploração da mão de obra feminina. No Brasil, o movimento pelos direitos da mulher nasceu em meio aos grupos anarquistas no início do século 20. A principal reivindicação era justamente melhores condições de trabalho.

Dias e Soihet (apud Céli Regina Jardim Pinto, 2017, n.p.) fazem um breve apanhado histórico da situação da mulher na época:

\footnotetext{
Na década de 1950, trabalhar fora de casa aceito apenas para mulheres pertencentes às camadas populares sociedade, em que o imperativo de sobrevivência sobrepunha quaisquer preconceitos ou tabus, muito embora essas mulheres sofressem toda sorte de abusos no ambiente de trabalho e ao transitar pelas ruas. Nas elites e classes médias urbanas, o lugar sagrado da mulher era lar, cumprindo seu papel de mãe santificada, pele menos nos discursos da família ideal, sendo, portanto, desaconselhável e mesmo vetado ter vida pública.
} 
Em março, comemora-se o Dia Internacional da mulher, mas esse mês ficou marcado como o mês das mulheres por conta de uma tragédia, um incêndio em uma fábrica de tecidos em Nova Iorque, que vitimou 130 operárias que morreram queimadas no dia 25 de março de 1911.

É importante destacar o clamor social que imperava na época e que acabou servindo como pano de fundo para início da luta das mulheres pelas condições mais dignas de trabalho, respeito e salários mais justos.

Glaucia Cristina Candian Fraccaro (2018, n.p.) ensina:

As greves se espalharam por diversas fábricas. Essas mobilizações eclodiram face aos efeitos da Crise de 1929, que se agravara internacionalmente. Desemprego e redução dos salários tornavam as condições de vida mais difíceis. Os empresários repassavam os custos da crise em forma de aumento da jornada de trabalho, que havia sido reduzida para conter estoques e produção de mercadoria, sem aumento dos salários. Esses eram os motivos que agitaram as greves iniciadas logo após a posse do governo que havia operado a Revolução de 1930.

De acordo com a historiadora Mônica Karawejczyk (2019) a luta feminina ganhou força por conta do movimento das sufragistas nas décadas de 1920 e 1930. Em 1932, elas conseguiram o direito ao voto na Constituição promulgada por Getúlio Vargas. A referida autora ensina:

O movimento sufragista surgiu como uma resposta direta à exclusão das mulheres da política, arena na qual as leis são feitas. Algumas mulheres passaram a acreditar que as muitas desigualdades legais, econômicas e educacionais - contra as quais se confrontavam - jamais seriam corrigidas enquanto os homens não tivessem que prestar contas a um eleitorado feminino. Assim, resolveram se unir para, juntas lutarem por seus direitos. $\mathrm{O}$ que distinguiu o movimento, em todas as partes que ocorreu, era que mulheres, de diferentes classes, raças, de graus de instrução e riqueza das mais diversas, se uniram em torno do mesmo objetivo, pois apesar das diferenças todas eram iguais na exclusão do mundo político. A conquista do voto era percebida por essas mulheres como um meio para atingir outros fins e não como um fim em si. Nesse sentido, o movimento sufragista brasileiro fez parte de um interesse específico das mulheres que como um grupo organizado, tinham uma demanda especial: o reconhecimento da sua cidadania através do direito de votar e serem votadas.

As mulheres são a maioria da população e no eleitorado brasileiro, mas na política ainda são minoria. Existe todo um caminho percorrido na trajetória da mulher na política brasileira desde a conquista do direito ao voto, à ocupação de cargos de chefia nos poderes do Estado.

Schuma Schumaher e Érico Vital Brazil (2003, p. 37) ensinam que em janeiro de 1929 Luiza Alzira Açoriano Teixeira foi eleita a primeira prefeita no Brasil e na América Latina. Ela assumiu a prefeitura de Lajes no Rio Grande do Norte com 6o\% (sessenta por cento) dos votos. Uma Lei Estadual de 1927 permitiu que as mulheres votassem e fossem votadas, mas no resto do país esse direito só foi conquistado em 1932 com o primeiro código eleitoral e colocado em prática no ano seguinte para a eleição da Assembleia Nacional Constituinte. A médica Carlota Pereira de Queiroz foi eleita a primeira Deputada Federal, mas naquela época o voto era permitido apenas para as mulheres que tinham uma profissão remunerada o que só mudou com o código de 1965 que está em vigor até hoje.

De uma forma ou de outra, as mulheres sempre estiverem presentes na história política do país, ainda que relegadas a um segundo plano. Marcelo Siqueira Ridenti (1990, p.1) ensina que a participação feminina na política nos idos dos anos 60 e 70 foi diferenciada uma vez que as mulheres influenciaram ativamente a cena política da época tanto para apoiar o regime militar de 1964, quanto para combatê-lo.

Schumaher e Brazil (2003, p. 36) acima citados pontuam: 
Os avanços no campo social ea conquista dos direitos civis hoje vivenciados pelas mulheres são resultado do esforço individual e coletivo de milhares e milhares de brasileiras que, inconformadas com a sua condição, se rebelaram contra a situação estabelecida. Foram índias contra a violência imposta pelos colonizadores, negras contra a escravidão e brancas contra as limitações que as confinavam ao mundo provado.

Chegar a essa realidade não foi fácil. Foram anos de luta para que as mulheres conquistassem o direito de votar e de serem votadas. A historiadora Karawejczyk (2019) anteriormente referenciada chama atenção para a questão ainda muito latente desde os primórdios, e que infelizmente perdura no que diz respeito a constante tentativa de diminuição da figura feminina na sociedade como um todo e na política:

\footnotetext{
Desde antes da implantação da República, mulheres apareceram contestando o seu lugar no mundo público, sofrendo as mais variadas críticas e admoestações. A permanência e a insistência de um tipo de argumento baseado na incapacidade feminina para lidar com o mundo público e político é encontrado em vários momentos da nossa história. Piadas, charges, e zombarias das mais diversas eram utilizadas como uma forma de inibir/ desacreditar/humilhar as mulheres que procuravam se inserir no espaço público e tiveram ampla difusão na imprensa do país [...] Assim, tentar mudar os costumes que restringem o papel feminino ao mundo doméstico, tornou-se uma das principais barreiras que deveriam ser vencidas por aquelas que desejavam participar das lides eleitorais.
}

Com a entrada em vigor da lei das eleições em 1997 as mulheres tiveram garantias de participação nas vagas dos partidos e coligações. A legislação eleitoral buscou assegurar a participação das mulheres na política de uma forma mais impositiva ao disponibilizar aos partidos a faculdade deles assegurarem a participação de 30\% (trinta por cento) das mulheres no legislativo. Posteriormente em 2009, com a minirreforma eleitoral essa faculdade se tornou uma obrigatoriedade fazendo com que os partidos necessariamente ocupassem pelo menos $30 \%$ (trinta por cento) das suas candidaturas com mulheres.

Simone B. Bohn (2008) escreveu o artigo "Mulher para presidente do Brasil? Gênero, e política na perspectiva do eleitor brasileiro.” À época, Simone fez os seguintes questionamentos: "Até que ponto os eleitores brasileiros estão dispostos s aceitar que uma mulher seja eleita e assuma o posto de Presidente da República do Brasil? Em que medida apoiam o princípio da igualdade de gênero na esfera política formal?". Dois anos depois, essas perguntas foram respondidas, pois em 2010, Dilma Roussef foi eleita a primeira mulher presidente da República, no Judiciário a ministra Ellen Gracie foi a primeira a ocupar a presidência do Supremo Tribunal Federal (STF) em 2006, em 2012 a ministra do STF Carmen Lúcia se tornou a primeira mulher a presidir o Tribunal Superior Eleitoral e também em 2012 pela primeira vez um tribunal superior teve a sua maioria ocupada por mulheres.

\section{PARTICIPAÇÃO FEMININA NA POLÍTICA BRASILEIRA}

Além do art. $5^{\circ}$ da Constituição Federal de 1988 que diz que “Todos são iguais perante a lei, sem distinção de qualquer natureza [...]" existem leis no Brasil que buscam dirimir a desigualdade entre homens e mulheres que ocupam espaços de poder na política. Contudo, os meios sociais e políticos são reflexos da sociedade. Sociedade essa que é desigual da maneira que trata as mulheres e as levam a um ambiente público.

Luciana Panke e Sylvia Iasulaitis (2016, n.p.) fazem a seguinte colocação: 


\begin{abstract}
Ainda que vários países apliquem leis de quotas de gênero, a equidade por enquanto está longe de ser alcançada. O universo da política é, ainda eminentemente masculino. As fotos de encontros de lideranças políticas mundiais, por exemplo, atestam com fidedignidade tal quadro. E isso não se aplica somente em termos quantitativos, mas, sobretudo, qualitativos. É possível afirmar que as regras do jogo político são fundamentalmente masculinas.
\end{abstract}

Sempre existiu essa dicotomia entre o público e o privado, onde o público era reservado aos homens e o privado que envolvia as questões do lar, de se recatar, não se mostrar, de cuidar dos filhos era dedicado à mulher, então crescer nesses espaços públicos exponencialmente masculinos, tendo direito à voz e respeito torna quase impossível para a mulher adentrar nesses ambientes que historicamente lhe foram negados.

Novamente, Panke e Iasulaitis (2016, n.p.) já mencionadas fazem a seguinte observação:

\begin{abstract}
Nos últimos anos, a América Latina vem se destacando por ter no governo de seus países representantes de esquerda e por eleger mulheres presidentes. Nesse quesito, nos deparamos com uma realidade que expõe a matriz cultural que também rege esses países: as relações assimétricas de gênero. Para as mulheres não é fácil destacar-se em um universo predominantemente masculino como é a política.
\end{abstract}

Para uma mulher conseguir respeito em um espaço dominado por homens é um processo que possui um peso cultural difícil e não se trata apenas de questão de força de vontade levando-se em consideração que existe toda uma cultura que privilegia o homem perante as decisões e posicionamentos políticos dentro da estrutura da sociedade social, política e economicamente organizada.

De acordo com Daniel Silveira (2018), em ranking de 190 países sobre presença feminina em parlamentos, o Brasil ocupava a $152^{2}$ posição. Esse dado foi divulgado dia 07 de março de 2018 pelo Instituto Brasileiro de Geografia e Estatística (IBGE) em parceria com a organização internacional Inter-Parliamentary Union (IPU) sediada na Suiça e que tem como objetivo mediar os contatos multilaterais dos países.

Embora haja lei de cotas para mulheres nos partidos e coligações ainda existe uma grande disparidade feminina na política em comparação ao número de homens.

Nas palavras de Silveira (2018):

Apesar de o Brasil ter legislação específica para garantir a presença feminina na política, o país amarga intensa desigualdade quanto à ocupação de cadeiras parlamentares pelas mulheres. Em um ranking de 190 países, o Brasil ocupa a $12^{2}$ a posição em relação ao percentual de parlamentares homens e mulheres na Câmara dos Deputados.

A divulgação desses dados torna-se de extrema importância uma vez que a partir deles pode-se elaborar políticas públicas voltadas a garantir o maior acesso de mulheres aos espaços políticos de poder. Ainda de acordo com Silveira (2018):

O IBGE destacou que desde 1995 o Brasil possui legislação específica que prevê cotas eleitorais, reservando às mulheres um percentual mínimo de candidaturas nas eleições proporcionais. Somente em 2009, no entanto, essas cotas se tornam obrigatórias. Pela lei, deve haver no mínimo $30 \%$ e no máximo $70 \%$ de candidaturas de cada sexo, para cada partido ou coligação partidária. A legislação rege as candidaturas e é cumprida. Todavia, ela não se reflete no resultado das eleições.

Como foi dito anteriormente, o Brasil ocupa hoje, as últimas posições no ranking mundial de igualdade no parlamento feito com mais de 190 países e mesmo com o aumento 
de deputadas eleitas o Brasil não se aproxima ainda de países como Argentina, Afeganistão e Estados Unidos.

De acordo como matéria de $\mathrm{O}$ Globo, publicada em 28 de janeiro de 2018 até mesmo os Estados Unidos apresentam uma baixa representatividade feminina no parlamento. A seguir seguem os dados apresentados:

\footnotetext{
Dados do Banco Mundial e do Inter-Parliamentary Union mostram que os Estados Unidos estão na 99a posição em participação feminina no Legislativo, em uma lista de 187 nações. Apenas 19,4\% dos membros da Câmara dos Representantes são mulheres, patamar inferiorà maioria das nações europeias e muitos países latinos (México, incluído) e muçulmanos (como Arábia Saudita e Emirados Árabes). O peso feminino é inferior até mesmo a muitos "países de merda” supostamente citados por Trump em uma negociação parlamentar, como El Salvador e diversas nações africanas - embora ainda fique acima do Brasil na 157 posição com 10,7\% e do Japão e Coreia do Sul.
}

Os desafios não param para ninguém, mas não param muito mais para quem é mulher, mãe, avó, para mulheres negras etc. São muitos os obstáculos enfrentados pelas mulheres, caminhos longos que são percorridos com determinação e coragem.

Para Claudia Maria Finamore e João Eduardo Coin de Carvalho (2006, n.p.) as diferenças de gênero na questão política acabam influenciando na forma como homens e mulheres irão lidar com a coisa pública, uma vez que a educação de meninos e meninas é dada de forma diferenciada.

Finamore e Carvalho (2006, n.p.) entendem a questão da seguinte forma:

\begin{abstract}
Os estudos sobre a participação da política das mulheres e a maneira como elas têm sido representadas pelos meios de comunicação e pelos eleitores oferecem algumas pistas para se entender as dificuldades envolvidas em uma participação política feminina mais efetiva. [...] já que as mulheres teriam uma agenda política e um trato com a res pública claramente diferenciados daqueles tipicamente masculinos. Mulheres ocupando cargos públicos legislativos, por exemplo, têm sistematicamente dirigido seus interesses para temas feministas, formando frentes de defesa das mulheres, seja em relação à violência contra a mulher, direitos reprodutivos ou saúde da mulher.
\end{abstract}

A identidade de quem governa tem efeitos enormes sobre os tipos de políticas públicas que são implementadas. A eleição de políticas mulheres não muda apenas o tipo de gasto público, mas também gera efeitos significativos sobre os resultados de saúde e educação. Pesquisadores descobriram que em assembleias estaduais que elegeram mais mulheres há uma diminuição significativa das taxas de mortalidade infantil neonatal e, além disso, localidades que elegem mais mulheres tem uma maior proporção de crianças que terminam o ensino fundamental. Daí a importância de cada vez mais mulheres ocuparem espaços públicos de poder, daí a importância da tão falada "representatividade".

\title{
4 DESAFIOS PARA AMPLIAÇÃO DA REPRESENTAÇÃO FEMININA NA POLÍTICA BRASILEIRA
}

Clara Araújo (2014, n.p.) ensina que "a partir dos anos 1990 muitos países adotaram uma política afirmativa na esfera institucional visando a alterações na presença feminina nos espações decisórios".

Para Daniela Leandro Rezende (2017) a adoção de políticas públicas voltadas para a questão da inserção da mulher nos espaços de poder, como as cotas de gênero e reservas de 
recursos do fundo partidário para o estímulo a participação das mulheres na política ainda não são suficientes para garantir o aumento da representatividade feminina nos espaços políticos majoritariamente ocupados por homens. Exemplo disso é o baixo índice de mulheres eleitas em qualquer pleito eleitoral dos últimos anos, mesmo após a criação de mecanismos de ações afirmativas que visaram à inserção de cada vez mais mulheres na vida política.

Para Paiva, Souza e Lopes (2004, p. 370-371 apud Panke; Iasulaitis 2016, n.p) tal fato é de simples explicação:

É evidente que existem diversas variáveis intervenientes que influenciam a atuação das mulheres na política, tanto ligadas ao arranjo político-institucional quanto à cultura política, em uma relação de fortalecimento recíproco. A sub-representação feminina não é um fenômeno unicasual.

Em que pesem todas as ações e políticas públicas que visam à inserção das mulheres na política, Rezende (2017) anteriormente mencionada faz a seguinte observação:

[...] é importante destacar que permanece o desafio de eleger mais mulheres, mas não se pode esquecer que esse se articula à necessidade de garantir que às mulheres já eleitas sejam assegurados recursos políticos que potencializem mudanças em direção à maior representação de mulheres, garantindo sua presença em todas as instâncias da política institucional.

Falta uma motivação maior para as mulheres se candidatarem, talvez no âmbito partidário não exista esse estímulo para as mulheres atuarem dentro da vida partidária e posteriormente se lançarem como candidatas e isso acaba refletindo no próprio Congresso Nacional onde a participação feminina, embora hoje em dia esteja maior do que nunca, ainda assim, é em um número bastante aquém do esperado. Aparentemente, um dos grandes desafios para o aumento da participação feminina na política perpassa pela implementação de políticas públicas que incentivem as mulheres a ocuparem espaços públicos.

Jussara Reis Prá (2014, n.p.) pontua:

Nomeadamente, desdea luta pelo direito ao voto, as organizações feministas e de mulheres
seguem partilhando experiências de mobilização nacional, regional e internacional.
Por esses caminhos as mulheres ampliam seus espaços de participação e qualificam os
conteúdos da agenda pública com o debate e a prática da democracia partidária. Por
conseguinte, na medida em que as mulheres questionam os princípios da democracia
moderna e os déficits de seus direitos políticos abrem um amplo campo de ação política.

No Brasil o eleitorado de mulheres é maior do que o masculino e, no entanto a representação político partidária da sociedade é feita pelos homens.

Para Araújo (2016, n.p.) medidas de ações afirmativas na política podem jogar um papel relevante para estimular à participação das mulheres na política.

É necessário tempo de televisão, recursos, proteção, sobretudo para as mulheres que estão na linha de frente tratando de questões extremamente sérias como tráfico, violência, insegurança justamente nas áreas onde as pessoas estão mais vulneráveis.

A representação feminina no Congresso Nacional, por exemplo, continua não sendo de responsabilidade, pois as mulheres continuam sendo chamadas para a política apenas para cumprir uma cota, uma meta. As reais chances ainda não estão sendo dadas. Algumas mulheres no Congresso são esposas, mães, filhas de algum político de renome. A representação feminina é difícil, mas existe e através das políticas públicas de incentivo, a tendência é melhorar. 
O jornalista Jamil Chade (2015), em artigo publicado no jornal O Estadão de São Paulo apontava que o Brasil tinha menos mulheres no Legislativo que o Oriente Médio. Chade faz a seguinte observação:

Também estão em posição melhor que o Brasil diversos países de maioria muçulmana onde, segundo ONGs como Anistia Internacional, a situação da mulher nem sempre é de igualdade de condições com os homens e onde violações aos direitos humanos são frequentes.

É sabido que pouca coisa mudou de lá para cá. Segundo Chade (2015), dados divulgados pela UIP davam conta que o Brasil possuía uma das menores taxas do mundo em número de mulheres dentro do Congresso Nacional.

O objetivo da divulgação desses dados era justamente chamar atenção para que os países promovessem uma participação maior das mulheres na política.

É necessário um conjunto de medidas e não apenas uma só, uma vez que acaba não surtindo o efeito esperado e até mesmo pode minar os benefícios que com muito esforço foram alcançados.

As mulheres precisam ter voz, respeito. Aliás, a mulher faz política econômica, em casa, nas relações, no trabalho e em todos os lugares.

\section{CONSIDERAÇÕES FINAIS}

O primeiro passo das mulheres na política brasileira ocorreu em 1932. Nesse ano elas conquistaram o direito ao voto e o poder de se candidatar a um cargo político. Em 1933, a primeira deputada federal brasileira se elegeu, em 1979 a primeira Senadora foi eleita e em 2010 o Brasil integrou a lista dos seis países da América Latina a eleger uma mulher para a presidência da República. Mesmo depois de mais de oito décadas de uma conquista histórica a presença de mulheres no Congresso Nacional e no poder executivo ainda é bem pequena. Depois de anos de luta, as mulheres alcançaram a presidência da República, plenários de Tribunais Superiores, ministérios etc. Não se pode comparar a situação da mulher de hoje com a de anos atrás, mas para uma sociedade mais justa e igualitária, muita coisa ainda precisa mudar. O palácio do planalto foi uma conquista imensa, mas o caminho das mulheres rumo à igualdade ainda é longo. $\mathrm{O}$ número de deputadas federais aumentou e o de mulheres candidatas quase dobrou, mas ainda assim, a representatividade feminina na política ainda é baixa.

Quando as mulheres conseguirem que o que está previsto nas políticas afirmativas seja inserido na sociedade como um todo, pensando em conselhos de classe, representações de categorias e representações sindicais, por exemplo, ambientes ainda muito dominados pelos homens será possível atestar os efeitos práticos destas políticas públicas voltadas para o gênero feminino que objetivam o aumento da participação das mulheres na política. Sendo essa inserção muito importante e ocorrendo de modo gradual, existe a necessidade de que isso se permeie na sociedade e em todas as instituições.

Desde quando a primeira mulher votou as conquistas femininas no processo eleitoral nunca ocorreram de uma hora para outra. Na realidade essa inserção da mulher na vida política de certa forma é um reflexo da luta das mulheres para serem inseridas em mercados e espaços que tradicionalmente eram vetados a elas. Existem marcos e avanços, mas essas conquistas não foram automáticas e dependem de atuações constantes através de ações políticas afirmativas voltadas ao aumento da participação política das mulheres. 
Se de fato é ilógico imaginar uma pessoa que não tenha nenhuma deficiência física falando sobre as dificuldades que ela nunca enfrentou para uma plateia de pessoas especiais ou uma pessoa branca falando para uma plateia negra sobre racismo emitindo opiniões sobre algo que ele/ela claramente nunca sentiu na pele, torna-se igualmente ilógico permitir que apenas homens legislem sobre questões e políticas públicas voltadas para mulheres.

Como confiar as questões que versam sobre desigualdade de gênero, sobre minorias, para opinar no lugar de fala da mulher sobre direito da mulher de ir e vir sem ser estuprada na rua, sobre aborto, sobre direito de não serem assediadas, sobre objetificação do corpo feminino a um grupo de homens, sendo em sua grande maioria ricos ou de classe média, privilegiados que nunca precisaram se preocupar com minorias porque nunca vivenciaram essas dificuldades de fato?

A voz da mulher precisa ser ouvida e exposta dentro de uma demanda que era negligenciada antigamente. Politica não é uma demanda apenas de homens. A mulher precisa lutar pelo seu espaço para construir uma sociedade mais segura, e igualitária para si mesma, suas mães, filhas e netas.

O descompasso entre mulheres candidatas políticas efetivamente eleitas pode ser atribuído à falta de apoio material a essas mulheres em que pese a legislação e a política de cotas dentro dos próprios partidos políticos e também ao fato de candidatos que já são parlamentares obterem uma taxa de sucesso maior em suas recandidaturas.

A participação feminina na política faz toda a diferença porque o olhar sensível e da determinação que a mulher tem em qualquer área seja na saúde, na educação, no meio ambiente, na assistência social, enfim, em todas as áreas é determinante para que ocorram transformações sociais.

Uma das críticas que fazemos à cota para mulheres na política, embora entendamos que como primeiro passo rumo à diminuição do abismo entre a participação masculina e feminina seja absolutamente necessária é o fato de que algumas distorções foram geradas em virtude desta lei, pois existe um número alto de mulheres que chegam a se candidatar, mas não recebem um único voto, nem mesmo delas mesmas. Isso faz com que os partidos corram atrás de mulheres para cumprirem a lei fazendo com que burlem o sistema apresentando candidaturas falsas ou "laranjas" para poder cumprir a cota partidária. Essa é uma das reações negativas possíveis. Entendemos que a lei de cotas atua na consequência, no efeito e não na causa do problema que vem antes. Os partidos cravam o mínimo de $30 \%$ (trinta por cento) de mulheres candidatas, uma vez que a lei os obriga, mas a cota ainda não se converteu em votos e em mulheres efetivamente eleitas para cargos políticos.

As mulheres não precisam e não devem se candidatar apenas para cumprir cotas, e sim para participar e promover mudanças no cenário político, econômico e social. A mulher faz diferença, tem capacidade de modificar as coisas. As mulheres sabem, podem e são capazes.

A participação feminina na política é importante, pois é necessário que mulheres atuem e falem por mulheres e para mulheres. É preciso que as instituições olhem e apoiem as mulheres na política afinal elas precisam representar a maioria de eleitores do país, mas não apenas isso, a presença feminina no campo da política traz benefícios para toda a população, além de trazer igualdade de gênero, algo essencial na sociedade atual. Com a liderança feminina na politica as mulheres se tornam mais engajadas nas discussões cívicas, e mais, as minorias são mais propensas a denunciarem os crimes cometidos contra elas e o nível educacional das adolescentes, bem como suas aspirações de carreira aumentam, construindo-se um campo fértil para maior igualdade de gênero.

A participação das mulheres nos espaços de poder seja no Congresso, Assembleias ou Câmaras municipais são muito poucas. A igualdade de gênero e a ampliação da participação das 
mulheres nos espaços institucionais de poder apresentam um grande desafio. Enfrenta-se uma grande dificuldade que é a de se viver em uma sociedade machista, muito violenta ainda com relação ás mulheres e que reproduz no imaginário popular que a política não é "coisa de mulher" e isso acaba tendo impacto negativo até mesmo na disposição das mulheres de participarem ativamente de campanhas eleitorais, de partidos, de poderem serem realmente competitivas em um processo eleitoral. Esse problema precisa ser enfrentado em várias dimensões, não só dentro do parlamento fazendo o debate público sobre a importância da representatividade das mulheres e também nas políticas públicas.

É Importante ressaltar que a luta por ocupação das mulheres dos espaços de poder deve ser travada não apenas nos espaços de poder institucionais, pois uma luta atrai a outra e é preciso mais mulheres representadas de forma positiva na mídia, uma vez que a mídia tradicional contribui com a reprodução da cultura machista, é necessário mais mulheres no judiciário, na educação, dentro de casa etc. A luta exige uma transformação mais profunda de valores, de comportamento, da forma como a sociedade enxerga a vida e as próprias mulheres. $\hat{E}$ necessário se convencer a mulheres e homens de que a política é um lugar de todos. É necessário que a sociedade debata essa questão. As mulheres inclusive precisam acreditar mais na sua força política, competência, vontade de ajudar a transformar e de acabar com as desigualdades. Uma vez que as mulheres são $52 \%$ (cinquenta e dois por cento) da população segundos dados do Instituto Brasileiro de Geografia Estatística (IBGE) ao não interferirem na política, elas estarão abrindo mão de interferir no destino delas e dos próprios filhos.

A mulher pode e deve ocupar todos os espaços, ela pode estar onde ela quiser e a presença da mulher na política expressa a maturidade da democracia de uma sociedade. Cada vez mais a mulher está conseguindo o seu espaço. A mulher é multifacetada, pode ser mãe, esposa, dona de casa e presidente da República, se assim o desejar.

A mulher demorou a conquistar o direito ao voto, à expressão, suas vontades e seus espaços. Obviamente quando uma mulher conquista um espaço de destaque na sociedade, existe a cobrança dessa mesma sociedade em cima dessa mulher que além de lidar com isso, precisa lidar como sua própria autoexigência. Existe o medo de errar, de falhar, de não corresponder. Existe uma angústia, ansiedade, exigência e perfeccionismo. Mas a inserção das mulheres na política é um processo. Quanto mais mulheres assumirem esses espaços e quanto mais a sociedade se permitir ser menos preconceituosa essa ocupação de espaços políticos e de poder se fortalecerão e se tornarão naturais e serão um desdobramento comum, uma evolução natural da sociedade moderna.

Aproximar o número de representantes mulheres ao de homens na política é mais do que defender o direito das minorias, é garantir o pleno exercício da democracia.

\section{REFERÊNCIAS}

ARAUJO, Clara. Valores e desigualdade de gênero: Mediações entre participação política e representação democrática. Civitas, Rev. Ciênc. Soc., Porto Alegre , v. 16, n. 2, e36, June 2016 . Available from <http://www.scielo.br/scielo.php?script=sci_arttext\&pid=S1519$60892016000200008 \& \operatorname{lng}=e n \& n r m=i s o>$. access on 04 Jan. 2020. http://dx.doi. org/10.15448/1984-7289.2016.2.23143.

BOHN, Simone R.. Mulher para presidente do Brasil? Gênero e política na perspectiva do eleitor brasileiro. Opin. Publica, Campinas, v. 14, n. 2, p. 352-379, Nov. 2008. Available from 
$<$ http://www.scielo.br/scielo.php?script=sci_arttext\&pid=So104-62762008000200004\&lng=e n\&nrm=iso >. access on 04 Jan. 2020. http://dx.doi.org/10.1590/So104-62762008000200004.

BRASIL. [Constituição (1988)]. Constituição da República Federativa do Brasil. Vade Mecum Acadêmico de Direito. São Paulo: Rideel, 2018.

BRASIL. Lei № 9.096, de 19 de setembro de 1995. Disponível em: http://www.planalto.gov.br/ ccivil_03/leis/l9096.htm. Acesso em o1 dez. 2019.

CHADE, Jamil. Brasil tem menos mulheres no Legislativo que Oriente Médio. Disponível em: https://politica.estadao.com.br/noticias/geral,brasil-tem-menos-mulheres-no-legislativo-queoriente-medio,1645699. Acesso em: 04 jan. 2020.

FINAMORE, Claudia Maria; CARVALHO, João Eduardo Coin de. Mulheres candidatas: relações entre gênero, mídia e discurso. Rev. Estud. Fem., Florianópolis, v. 14, n. 2, p. 347-362, Sept. 2006. Available from <http://www.scielo.br/scielo.php?script=sci_arttext\&pid=So104-026X2 0o6000200002\&lng=en\&nrm=iso $>$. access on 04 Jan. 2020. http://dx.doi.org/10.1590/So104026X2006000200002.

FRACCARO, Glaucia Cristina Candian. Uma história social do feminismo: diálogos de um campo político brasileiro (1917-1937). Estud. hist. (Rio J.), Rio de Janeiro , v. 31, n. 63, p. 7-26, Apr. 2018 . Available from <http://www.scielo.br/scielo.php?script=sci_arttext\&pid=So10321862018000100007\&lng=en\&nrm=iso $>$. access on 04 Jan. 2020. http://dx.doi.org/10.1590/ s2178-14942018000100002.

KARAWEJCZYK, Mônica. O voto feminino no Brasil. Disponível em: http://querepublicaeessa. an.gov.br/temas/147-o-voto-feminino-no-brasil.html. Acesso em o3 jan, 2020.

O Globo. Confira como é a participação mundial de mulheres nos parlamentos. Disponível em: https://oglobo.globo.com/mundo/confira-como-a-participacao-mundial-de-mulheres-nosparlamentos-22337957. Acesso em: 05 jan, 2020.

PANKE, Luciana; IASULAITIS, Sylvia. Mulheres no poder: aspectos sobre o discurso feminino nas campanhas eleitorais. Opin. Publica, Campinas, v. 22, n. 2, p.385-417, Aug. 2016. Available from <http://www.scielo.br/scielo.php?script=sci_arttext\&pid=So104-62762016000200385\&ln $\mathrm{g}=\mathrm{en} \& \mathrm{nrm}=\mathrm{iso}>$. access on 14 Jan. 2020. http://dx.doi.org/10.159o/1807-01912016222385.

PINTO, Céli Regina Jardim. Elas não ficaram em casa. As primeiras mulheres deputadas na década de 1950 no Brasil. Varia hist., Belo Horizonte, v.33, n. 62, p. 459-490, Aug. 2017. Available from <http://www.scielo.br/scielo.php?script=sci_arttext\&pid=So104-87752017000200459\&lng $=$ en\& $\mathrm{nrm}=\mathrm{iso}>$. access on 04 Jan. 2020. http://dx.doi.org/10.1590/0104-87752017000200008.

PRA, Jussara Reis. Mulheres, direitos políticos, gênero e feminismo. Cad. Pagu, Campinas , n. 43, p. 169-196, Dec. 2014 . Available from <http://www.scielo.br/scielo.php?script=sci_ arttext\&pid=So104-83332014000200169\&lng=en\&nrm=iso $>$. access on 15 Jan. 2020. http:// dx.doi.org/10.1590/0104-8333201400430169. 
REZENDE, Daniela Leandro. Desafios à representação política de mulheres na Câmara dos Deputados. Rev. Estud. Fem., Florianópolis , v. 25, n. 3, p. 1199-1218, Dec. 2017 . Available from <http://www.scielo.br/scielo.php?script=sci_arttext\&pid=S0104-026X2017000301199\&lng= en\& $n r m=i s o>$. access on 05 Jan. 2020. http://dx.doi.org/10.1590/1806-9584.2017v25n3prezende.

RIDENTI, Marcelo Siqueira. AS MULHERES NA POLÍTICA BRASILEIRA: OS ANOS DE CHUMBO. Tempo soc., São Paulo, v. 2, n. 2, p. 113-128, Dec. 1990 . Available from <http:// www.scielo.br/scielo.php?script=sci_arttext\&pid=S0103-20701990000200113\&lng=en\&nrm=i so>. access on 04 Jan. 2020. http://dx.doi.org/10.159o/ts.v2i2.84806.

SCHUMAHER, Schuma, BRAZIL, Érico Vital. Um rio de mulheres: A participação das fluminenses na história do Estado do Rio de Janeiro. Rio de Janeiro, Redeh, 2003.

SILVEIRA, DANIEL. Em ranking de 190 países sobre presença feminina em parlamentos, Brasil ocupa 152 ${ }^{\underline{a}}$ posição. Disponível em: https://g1.globo.com/politica/noticia/em-ranking-de-19opaises-sobre-presenca-feminina-em-parlamentos-brasil-ocupa-a-152-posicao.ghtml. Acesso em: 12 jan, 2020. 